9

\title{
Relations between electron content and peak density: regular and extreme behaviour
}

\author{
REINHART LEITINGER $\left({ }^{1}\right)$, LUIGI CIRAOLO $\left({ }^{2}\right)$, LEONARD KERSLEY $\left({ }^{3}\right)$, \\ STAMATIS S. KOURIS $\left({ }^{4}\right)$ and PAOLO SPALLA $\left({ }^{2}\right)$ \\ (1) Institute of Physics, Institute for Geophysics, Astrophysics and Meteorology (IGAM), \\ University of Graz, Austria \\ (2) Istituto di Fisica Applicata «Nello Carrara» (IFAC), Firenze, Italy \\ $\left(^{3}\right)$ University of Wales, Aberystwyth, U.K. \\ $\left(^{4}\right)$ Department of Electrical and Computer Engineering, Aristotelian University of Thessaloniki, Greece
}

Electron content statistics offers important information for planning and operation of various application systems that make use of the transionospheric propagation of radio signals. Electron content statistics meet with an important difficulty: the majority of data stem from observations on the radio signals of orbiting satellites. The database for vertical electron content derived from observations of radio signals emitted from geostationary satellites is only very small. Therefore it is important to make use of statistics for peak density from ionosonde measurements. Quantile statistics do not contain information about ionization extremes. Therefore it is necessary to complement the statistics with case studies which reveal unusual and extreme electron content structures in space and in time.

\subsection{INTRODUCTION}

(Total) Electron Content (TEC) is an important ionospheric characteristic for planning and operation of satellite navigation and communication systems. Thus the study of its behaviour and especially of its variability in time and space is essential. Since we have very long experience with $F 2$-layer peak density (gained from the square of critical frequency foF2) and since suitable ionospheric electron content data are scarce compared with the large number of $f o F 2$ data, it is very important to make use of peak density experience to gain better knowledge on temporal and spatial behaviour of TEC.

This can be done by means of a relation parameter, (equivalent) Slab Thickness t which is vertical electron content $I_{v}$ divided by (F2-) peak electron density $N m: \tau=I_{v} / N m$. Usually this quantity is given in $\mathrm{km}$.

\subsubsection{Notes on electron content (TEC)}

In this paper electron content means the height integral of electron density. It cannot be measured directly but has to be estimated from propagation effects on radio signals transmitted from artificial satellites. Therefore the primary observed quantity is approximately proportional to the integral of electron 
density along a slant ray path, slant electron content (sTEC). We gain an approximation to vertical electron content (vTEC) by means of a projection from slant to vertical at a «pierce point» on the straight line from the satellite receiver to the ground station in a suitably chosen «mean ionospheric height». It is important to note that vTEC is height integrated electron density from the ground to a «ceiling height» which depends on the orbital height of the transmitter and on the propagation effect used.

The Faraday rotation of linearly polarised signals was used in early studies of electron content. However, the relationship between the measured rotation and the content is not direct and it is necessary to assume a representative value for the longitudinal component of the electron gyrofrequency along the ray path in the analysis. In consequence, for the Faraday effect observed on the VHF signals of geostationary satellites the effective ceiling height is $2000 \mathrm{~km}$ and the relative slant to vertical conversion error is about $5 \%$ for receiving stations in mid latitudes (Titheridge, 1972). vTEC gained by means of propagation effects on the signals of geostationary satellites suffers from a smoothing effect: in general the ray from the ground station to the satellite is not meridional but cuts through longitudes which gives data smoothing in local time. Local time smoothing strongly affects the time interval around sunrise. Unfortunately we have not any longer geostationary Faraday beacons which had the considerable advantage of providing (nearly) constant observation geometry and an extremely good temporal resolution.

Of course variability and comparison with $f o F 2$ studies can also be made with TEC data from other sources, e.g., with the latitudinal cross sections provided by VHF/UHF beacons in nearly polar orbits. In case of the former Navy Navigation Satellites (NNSS, now NIMS - Navy Ionosphere Monitoring Satellites) the ceiling height is the orbit height of about $1100 \mathrm{~km}$. The propagation effect is the difference Doppler effect. Absolute vertical TEC suffers from the need of «calibration» but for low zenith angles the TEC differences over short distances are comparatively good data. The best way to reveal larger structures in vertical electron content is the combination of data from the receiving stations in meridional chains and «calibration» by means of the results of tomographic reconstruction.

In principle, a large quantity of vTEC data could be gained by means of the GPS beacons. As a first guess one is tempted to take the orbit height of $20000 \mathrm{~km}$ to be the ceiling height for vTEC. Since we are interested in ionospheric electron content we should correct for the contribution of the plasmasphere (see Ciraolo and Spalla, 1997, 1998; Ciraolo et al., 2001). If we succeed with this we end up with a «ionospheric» ceiling height of $2000 \mathrm{~km}$. For a critical review of GPS-TEC see Jakowski et al. (2004). At least on a statistical basis the difference between GPS-TEC and NNSS(NIMS)-TEC should give a good indication on the plasmaspheric vertical electron content. Some studies were initiated in the frame of COST 251 on a monthly median basis (Leitinger and Feichter, 2000) and continued in the frame of COST 271 (see, e.g., Ciraolo and Spalla, 1997, 1998; Ciraolo et al., 2001).

\subsubsection{Notes on slab thickness $\tau$}

1) Most of slab thickness data were gained by combining vertical electron content derived by means of the Faraday effect on the VHF signals of geostationary satellites with peak electron density derived from ionograms. Therefore the slab thickness ceiling height is $2000 \mathrm{~km}$ and we have to expect smoothing around sunrise. Since in general the geographic coordinates of the pierce point (in a mean ionospheric height of 400 or $420 \mathrm{~km}$ ) differ from the geographic coordinates of the ionosonde station, we have co-location problems, especially around sunrise. If the transmitter satellite is not truly geostationary (inclination $>0^{\circ}$ ) we should account for a local time variation of the Faraday rotation to sTEC and of the sTEC to vTEC conversion factors and of the pierce point coordinates.

2) For mid latitudes several slab thickness models have been published (e.g., Titheridge, 1973; Hajeb-Hosseinieh and Kersley, 1975; Kersley and Hajeb-Hosseinieh, 1976; Huang, 1983; Fox et al., 1991; Davies and Liu, 1991; Spalla and Ciraolo, 1994). They have in common: a) a slab thickness range between about $170 \mathrm{~km}$ and $320 \mathrm{~km}$ at low solar activity and between about 200 and $400 \mathrm{~km}$ at high solar activity; b) an increase in slab thickness with solar activity; c) for non-storm conditions on- 
ly a slight positive (Kersley and Hajeb-Hosseinieh, 1976) slab thickness dependence on magnetic activity. d) Under (major) magnetic storm conditions, not including strong positive storm effects, which occur in the American East Coast region, we can expect a slight daytime increase in slab thickness (of around 10 to $30 \mathrm{~km}$ ).

The pre-dawn slab thickness peak also seems to be a stable and regular feature, even if we allow for the interpretation problems we expect around sunrise.

3) Neglecting solar activity, diurnal and seasonal variations the overall mean slab thickness for Europe (around $42^{\circ} \mathrm{N}, 13^{\circ} \mathrm{E}$ ) can be given as $230 \mathrm{~km}$ with a standard deviation of $50 \mathrm{~km}$ (Spalla and Ciraolo, 1994). For high solar activity an average around $300 \mathrm{~km}$ probably is more appropriate (fig. 9.1). The overall means for the American East Coast sector are slightly higher: the mean from the model by Fox et al. (1991) is $267 \mathrm{~km}$ for an intermediate level of solar activity of $R_{12}=75\left(\tau=242 \mathrm{~km}\right.$ for $R_{12}=0, \tau=292 \mathrm{~km}$ for $\left.R_{12}=150\right)$. For the same set of data (re-
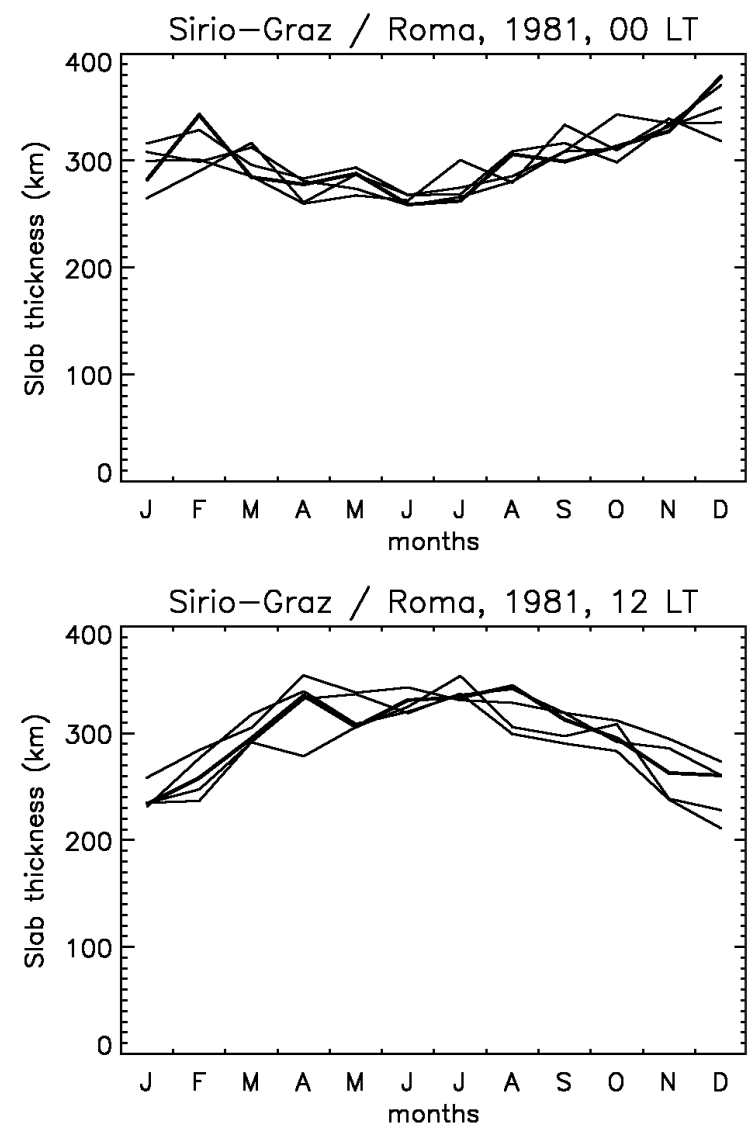

Fig. 9.1. Annual variation of equivalent slab thickness for 1981 from the combination of vertical electron content measured by means of the Faraday effect on the VHF signal of SIRIO at Graz (latitude of ionospheric point $\left.42.5^{\circ} \mathrm{N}\right)$ and peak electron density from the ionosonde data of Roma $\left(41.9^{\circ} \mathrm{N}, 12.5^{\circ} \mathrm{E}\right)$. Upper panel: $0 \mathrm{LT}$; lower panel: 12 LT (Leitinger, 1998). The different curves have been gained with the lower and upper deciles, lower and upper quartiles and with the medians. 
ceiving station Sagamore Hill, $42^{\circ} \mathrm{N}, 288^{\circ} \mathrm{E}$ ) Davies and Liu (1991) get for low solar activity a noontime $\tau=253 \mathrm{~km}$ and a midnight one of $260 \mathrm{~km}$. The corresponding high solar activity $\left(R_{12}=150\right)$ values are $\tau=318 \mathrm{~km}$ and $\tau=300 \mathrm{~km}$.

Figure 9.1 shows the annual variation of monthly mean slab thickness for 0 LT and 12 LT from the combination of Faraday-TEC measured on the VHF signal of SIRIO with peak density from the ionosonde station Roma $\left(41.9^{\circ} \mathrm{N}, 12.5^{\circ} \mathrm{E}\right)$.

4) In low latitudes we expect an increase in slab thickness towards the dip equator when the equatorial anomaly is on. However, this is a conclusion we have to draw from theoretical considerations: because of the configuration of the geomagnetic field much larger errors are involved in the interpretation of the Faraday effect on the VHF signals of geostationary satellite received at ground stations in low latitudes. Under solar minimum conditions Klobuchar et al. (1991) calculate a slab thickness peak near the dip equator of about $460 \mathrm{~km}$ for «average drift conditions» and of about $560 \mathrm{~km}$ for «high drift conditions». The solar maximum values are around $510 \mathrm{~km}$ both for «average» and «high drift conditions». Klobuchar et al. (1991) find that the region of enhanced slab thickness extends to dip latitudes around $\pm 34^{\circ}$. In experimental data the increase in $\tau$ with decreasing dip latitude is indicated by Huang (1983). His graphics indicate an overall mean for the receiving station Lunping (pierce point coordinates $23^{\circ} \mathrm{N}$, $122^{\circ} \mathrm{E}$, dip latitude $17^{\circ}$ ) of $\tau>300 \mathrm{~km}$ (unfortunately he gives no numbers).

5) Some slab thickness studies have been carried out with the purpose of assessing empirical and theoretical ionospheric models, some have been carried out to draw conclusions on vTEC variability from peak density variability.

\subsubsection{Notes on «worst cases» and «extremes»}

Assessment and feasibility studies for engineering applications are often based on «worst case» considerations. The probability that a «worst case» is exceeded must be very low $\left(<10^{-7}\right.$ is often quoted $)$. On the other hand it is not acceptable to take the smallest or largest observed value with a large margin to be «on the safe side» because this would mean low availability of an application system or unnecessarily high costs. The usual «worst case» concept does not work with nature data or events. Ground and near ground environmental data use rarity of event considerations, e.g., river flood levels that should not be exceeded more often than once a century.

The question of a «worst case» value or a «probably not more often than once per century exceeded» value of (slant and vertical) electron content needs qualification to obtain a reasonable answer.

1) The TEC database from Faraday effect and differential Doppler observations is very small compared with the peak electron density database. Furthermore, it is concentrated in a few regions of the world.

2) Despite a large amount of dual frequency receiving stations for GPS which have collected data over several years we have a very limited «TEC from GPS» data set only. This is because a) the receiving stations are far from being evenly distributed and especially for lower latitudes large regions like Africa must be considered as «white spots»; b) reliable vertical electron content data have been produced by means of GPS observations for a part of the present solar cycle only and this cycle must be considered a comparatively weak one which has not given really high solar activity values.

3) It is practically impossible to get a reasonably good prediction for the next solar cycle which means that experience from the present one might lead to wrong conclusions if the next solar maximum happens to be much stronger or much weaker than the 2000-2001 maximum.

4) Strong magnetic storms have to be considered as singular events which do not allow us to draw conclusions on a statistical basis. There are only a few really strong storms per solar cycle.

5) From time to time nature tends to produce «rare and irregular» events which affect small areas only. There are no statistics for such events and the probability is high that most of them have not been observed. 
The first qualification to the «worst case» question should be «exclude strong storms». For operational systems this qualification might be acceptable because we have reliable «storm indicators».

The second qualification should be «exclude rare events» which might produce unexpected smaller scale ridges and troughs. Collections of observed cases (see Section 9.5) help in demonstrating possible effects on application systems.

\subsubsection{Notes on monthly and hourly statistics}

The ionosonde network has taken over the concept of «synoptic» observations which was developed first by Gauss and Weber for geomagnetic observations and later for the observation of ground temperature and other meteorological parameters. Propagation effects on the signals of geostationary satellites too can be read from chart records or digitally in hourly or shorter regular intervals. This is not possible with orbiting satellites. Some ionosonde stations have produced long series of monthly and hourly medians and quartiles. In principle, it is possible to derive the deciles too. However, with 28 to 31 data (not accounting for equipment failure) it is not possible to derive quantiles below the lower decile or above the upper decile.

\subsection{ELECTRON CONTENT VARIABILITY DEDUCED FROM THE VARIABILITY OF PEAK ELECTRON DENSITY}

Concentrating on mid latitudes we should distinguish between a) short term variability, b) day to day variability, and c) storm effects.

The use of slab thickness allows us to transfer $N m(F 2)$ variability to vTEC variability. For small enough percent variability of critical frequency foF 2 we can assume percent variability of $N m(F 2)$ to be twice the percent variability of $f o F 2$. Except for pre-dawn conditions we can safely assume that within one hour $\tau$ does not change appreciably. Therefore we expect short-term relative vTEC variability to be twice the relative short-term variability of $f_{o F}$.

However, the day-to-day variability of slab thickness cannot be neglected. Therefore we expect that the «worst case» day to day variability of TEC is considerably higher than the corresponding variability of $N m(F 2)$. In mid latitudes a factor of 1.5 seems to be safe. In low latitudes we need a larger factor: the slab thickness values depend crucially on the status of the equatorial «fountain». To knowledge our no relevant studies have been made. From Klobuchar et al. (1991) it follows that we have to expect slab thickness variability at the dip equator from about $200 \mathrm{~km}$ (no $\boldsymbol{E} \times \boldsymbol{B}$ drift, «fountain off») to about $560 \mathrm{~km}$ (high $\boldsymbol{E} \times \boldsymbol{B}$ drift) for equinox and more or less average conditions. A «worst case» factor of 3 to 4 seems to be appropriate.

\subsection{RESUlts OF THE TEC VARIABILITY STUDIES OF COST 271}

Day-to-day and hour-to-hour variability is a permanent feature of the ionosphere and therefore meaningful predictions can only have statistical character, i.e. specify probabilities (Rawer, 1993; Rawer et al., 2003). The variability from hour-to-hour of any ionospheric characteristic is estimated from its hourly relative deviations, i.e. from the variation from hour-to-hour of the hourly daily values with respect to their corresponding monthly-median (e.g., Kouris and Fotiadis, 2002).

In this study we used hourly daily TEC data obtained observing the Faraday rotation affecting the signals emitted from geostationary satellites, measured at Florence from 1976 to 1982 and 1989 to 1991 , as well as GPS-TEC-data measured at Matera $\left(40^{\circ} \mathrm{N}, 16^{\circ} \mathrm{E}\right)$ from 1993 to 1999 . We also used hourly daily foF 2 measurements made at the station of Rome during the same periods. 

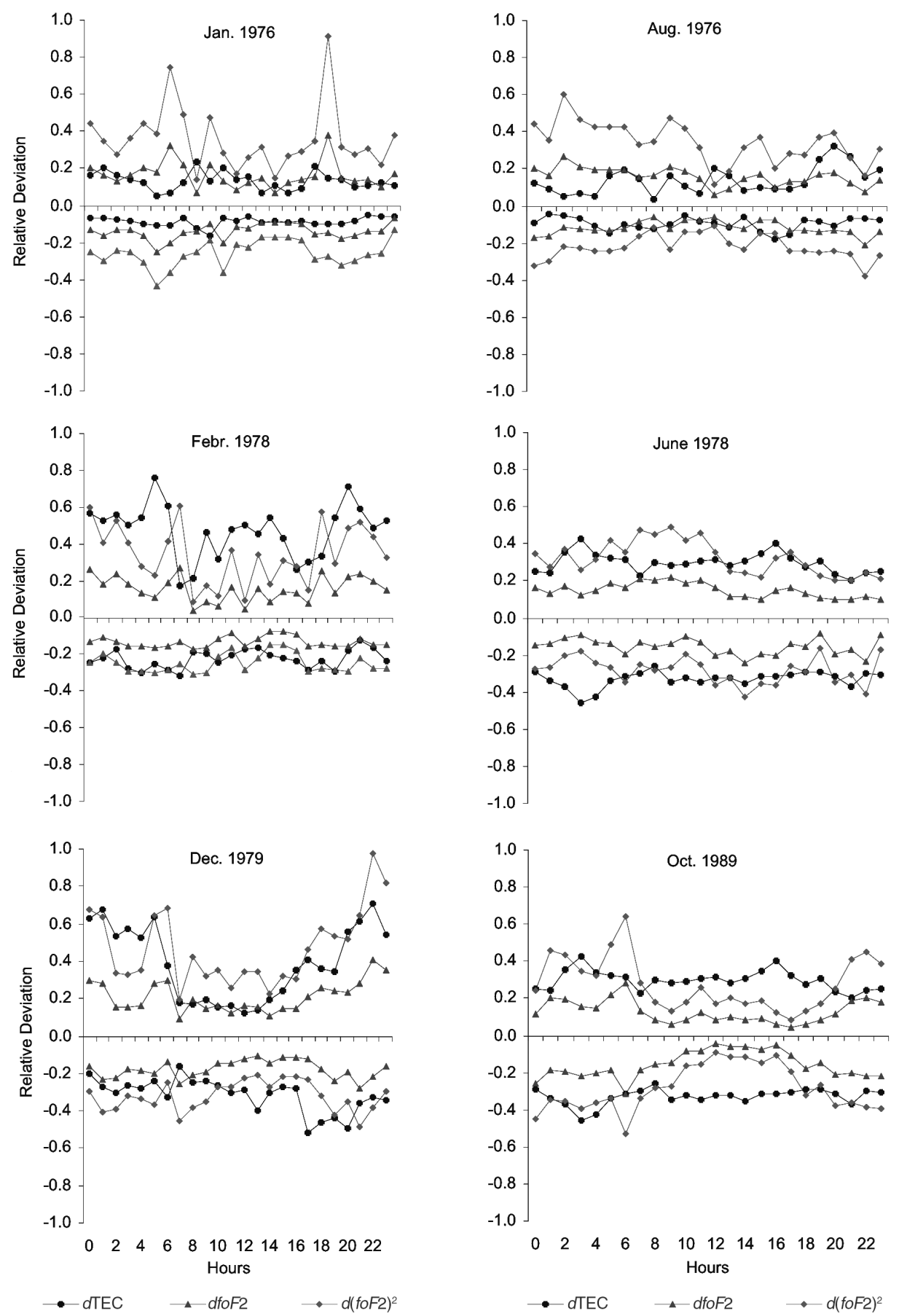

Fig. 9.2a. Upper and lower deciles in TEC, $f o F 2$ and $(f o F 2)^{2}$. Faraday rotation data have been used. 

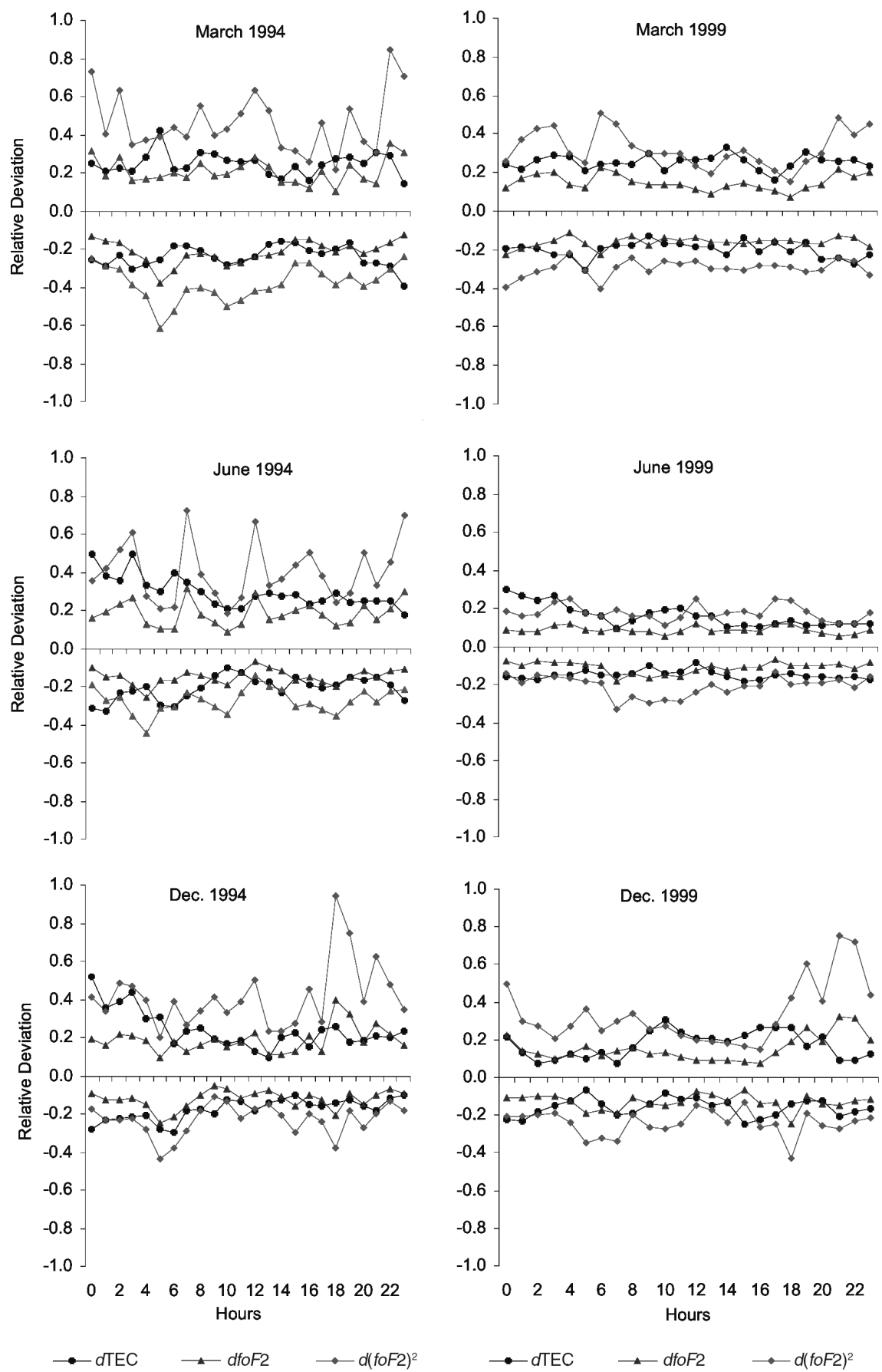

Fig. 9.2b. Upper and lower deciles in TEC, $f o F 2$ and $(f o F 2)^{2}$. GPS data have been used. 

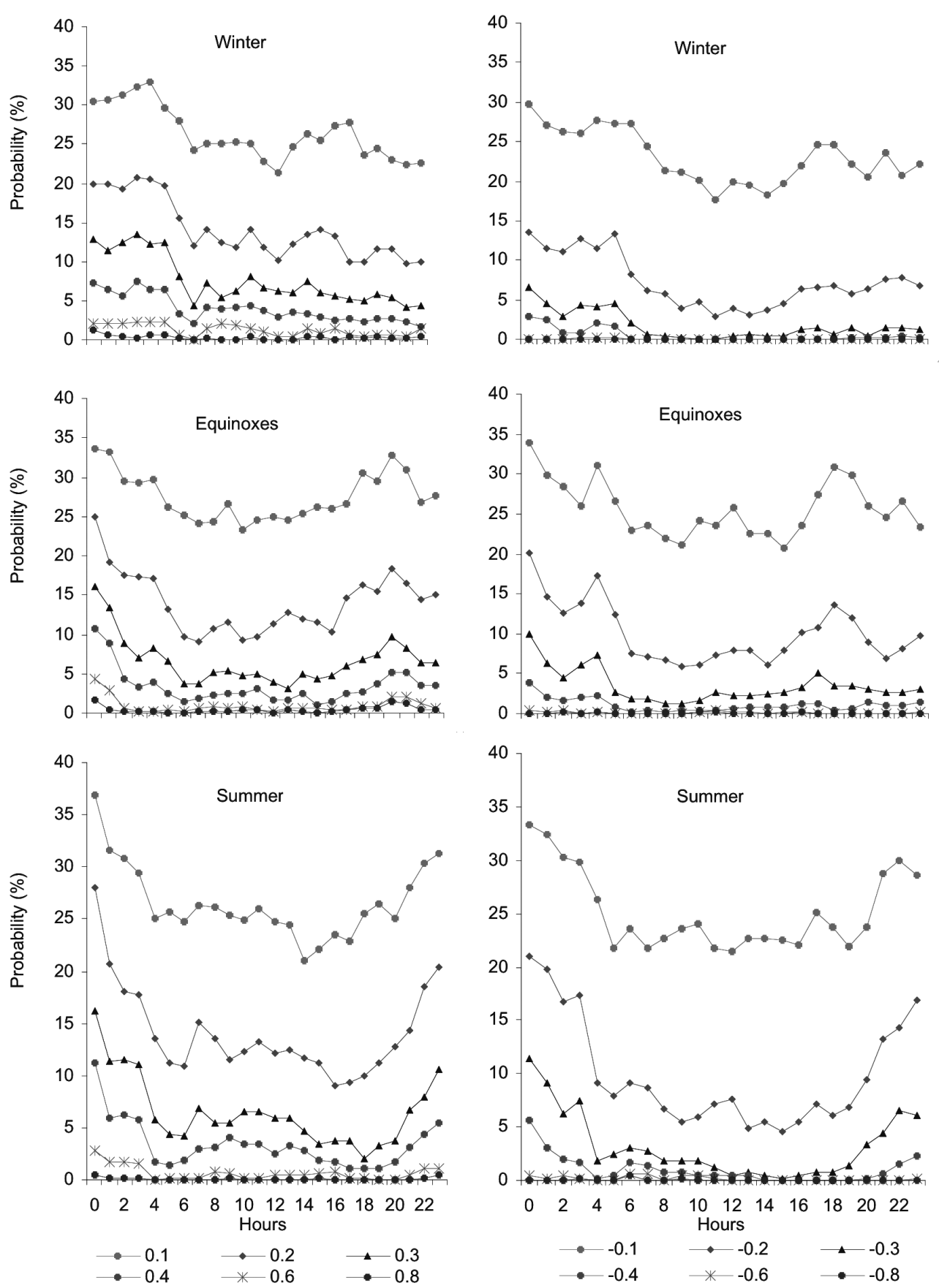

Fig. 9.3a. Probability that a given level, positive (left) or negative (right), of variability in TEC is exceeded at low solar activity (mid-latitudes). 

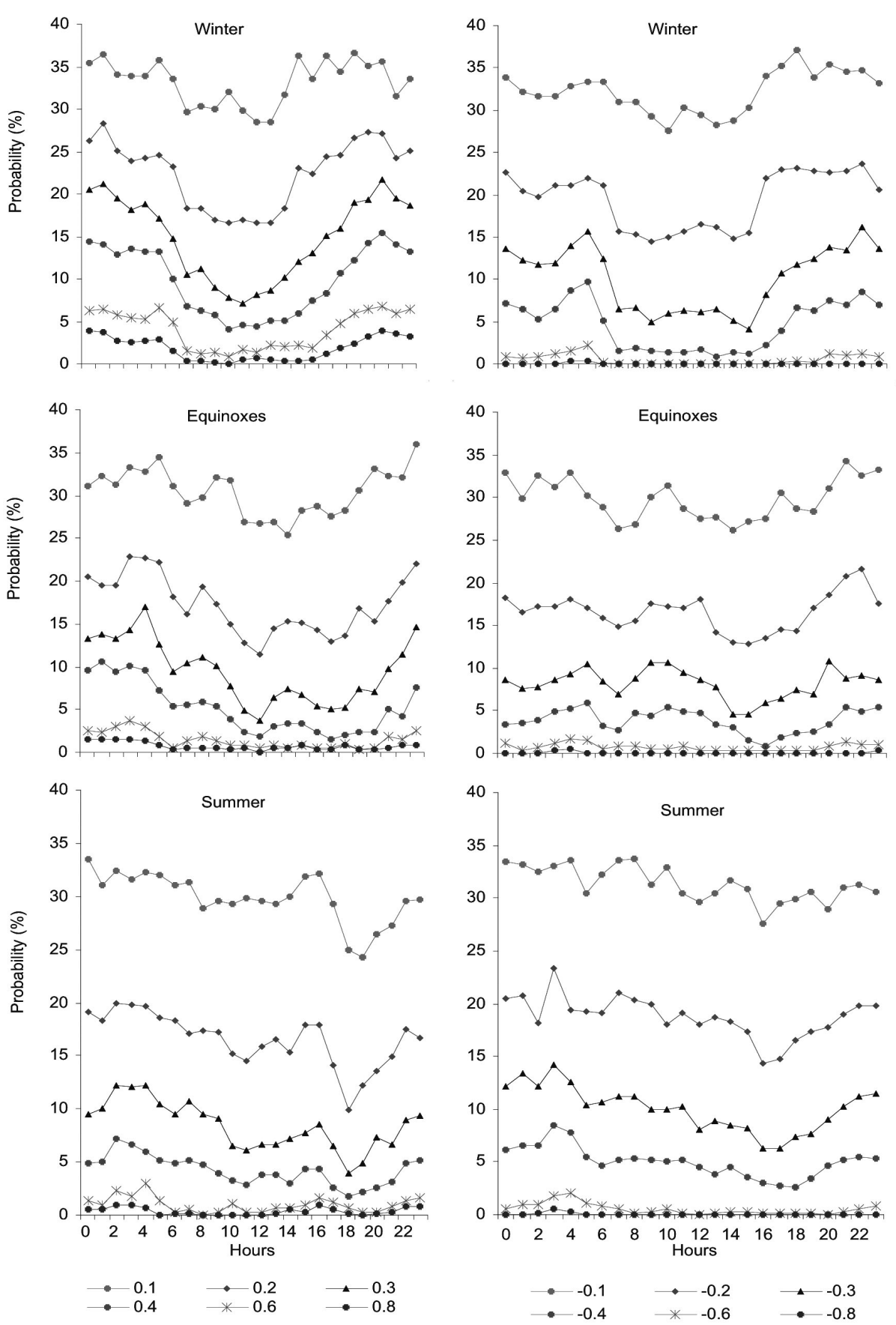

Fig. 9.3b. Probability that a given level, positive (left) or negative (right), of variability in TEC is exceeded at high solar activity (mid-latitudes). 
First we have evaluated the relative deviations of TEC, $f o F 2$ and $(f o F 2)^{2}$, respectively at each hour of each day/month/year. Then, we counted the upper and lower deciles of relative deviations in each hour of each month/year, for each parameter. By examination of the obtained results we have observed (Kouris et al., 2004) that the variability from hour-to-hour in TEC is close to that of foF2 during periods of low/medium solar activity and overlaps with that of $(f o F 2)^{2}$ at high solar activity.

Figure 9.2a,b as an example illustrates upper and lower deciles of variability in TEC, foF 2 and $(f o F 2)^{2}$, respectively at some randomly selected months/years using Faraday rotation data (fig. 9.2a) or GPS data (fig. 9.2b). It is evident from this Figure that the variability in TEC lies between the variability of $f o F 2$ and that of $(f o F 2)^{2}$ according to the solar activity and/or the disturbed state of the ionosphere.

During very disturbed conditions, as for instance in February 1978 or October 1989 (fig. 9.2a), the variability in TEC could be greater than that in maximum electron density. This might suggest that disturbances affect the topside more than the bottomside of the ionosphere. Indeed, it is found (Kouris and Fotiadis, 2002) that the variability in the critical frequency of the E-layer is much less than that in $f o F 2$, supporting the above statement. Moreover, the present investigation highlights that the variability exhibits its higher values mostly during nighttime hours, when disturbed conditions usually prevail and during winter-time (fig. 9.1). On the other hand, in summer time the variability seems to be rather independent of the time of day and of solar activity, although the lower levels of variability indicate a certain dependence on the phase of solar cycle. More investigation is needed.

It is worth assessing the range of variability in TEC and also the probability of occurrence of a given level of variability. The statistical analysis (Kouris and Polimeris, 2003) has shown that the upper levels of variability in TEC, i.e. positive deviations (enhancements) are higher than the lower (negative deviations). The former may reach values nearly twice those of the corresponding monthly-median values whereas the latter usually reach values up to $50 \%$ or $60 \%$ lower than the corresponding monthly-median values and are independent of season.

Figure 9.3a,b shows curves of probability that a given level positive or negative could be exceeded at low solar activity (fig. 9.3a) and high solar activity (fig. 9.3b). Figure 9.3a shows clearly that the probabilities are higher during the night-time hours and that especially in summer and equinoxes, whereas at high solar activity (fig. 9.3b) this is marked during winter. It is also evident that the probability of exceeding a positive or negative level of variability of the order of $60 \%$ higher of the corresponding monthly-median value is less than $2 \%$ except in winter at high solar activity (fig. 9.3b) where the probability of an enhancement of that order is just a little higher. From the same figures it can also be seen that the probability to exceed a given level is higher for positive deviations than for negative except in summer where there is practically no difference between enhancement and depression levels (fig. 9.2a,b).

\subsection{SOME ELECTRON CONTENT STATISTICS}

TEC from Faraday rotation data is very well suited for temporal statistics. The worldwide best data set is kept at the former Istituto di Ricerca sulle Onde Elettromagnetiche (IROE) at Florence (Spalla et al., 1983). The archive covers more than one solar cycle and contains vertical electron content with a time resolution of one minute. The relative, short-term accuracy is better than $2 \times 10^{14} \mathrm{~m}^{-2}(0.02 \mathrm{TEC}$ units). Here we show only a small sample from the statistics work done at Florence. The complete material with statistics for time intervals from one minute to one hour is available in the form of power point presentations. Figure 9.4a-d shows occurrence statistics (histograms) for vTEC time derivatives from all data (fig. 9.4a), high solar activity data (fig. 9.4b), medium solar activity data (fig. 9.4c) and low solar activity data (fig. 9.4d) (Ciraolo and Spalla, 1999). The time derivatives were gained as, $D_{t}=\left(I_{t+1}-I_{t-1}\right) / 2, I$ being vertical TEC. $D$ is given in TEC units per minute $\left(10^{16} \mathrm{~m}^{-2}\right.$ per minute). 



Fig. 9.4a-d. Distribution of the time derivative of TEC.

The second important source of data for TEC statistics is the latitudinal scans provided by the Navy Navigation Satellite System (NNSS, after decommissioning for shipboard navigation the remaining systems is called Navy Ionospheric Monitoring System - NIMS). From the latitude dependence of vertical electron content we can derive latitudinal gradients as the basis of statistics. Such studies have been done at Florence and at Graz.

\subsection{A SHORT OVERVIEW ON PECULIAR CASES AND RARE EVENTS}

With no intention for completeness a few examples are given for peculiar electron content structures and rare events. It is very likely that the majority of peculiar cases and rare events have not been observed. It is also likely that data archives contain interesting structures and «extremes» and it would be worthwhile searching through the archives. The samples presented were collected at Graz.

The most interesting case is shown in fig. 9.5: a narrow peak in mid latitudes which was «seen» during $5 \mathrm{~h}$ in the night October 8 to 9, 1984. It had disappeared on the morning of October 9 but due to the lack of NNSS passes the real duration of the event is not known. In longitude the peak was «seen» over more than $10^{\circ}$.

Figure 9.6 shows an example of large scale and large amplitude Travelling Ionospheric Disturbances (TIDs), fig. 9.6 gives a strong hint on the longitudinal gradients which can be coupled to TIDs (narrow fan beam structure). 


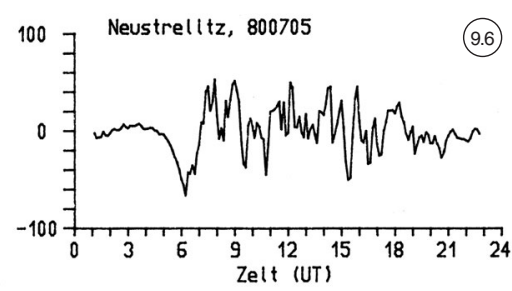

50 Graz, 800705
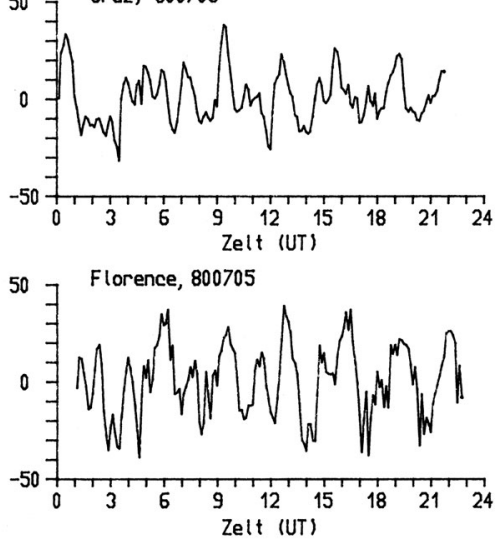

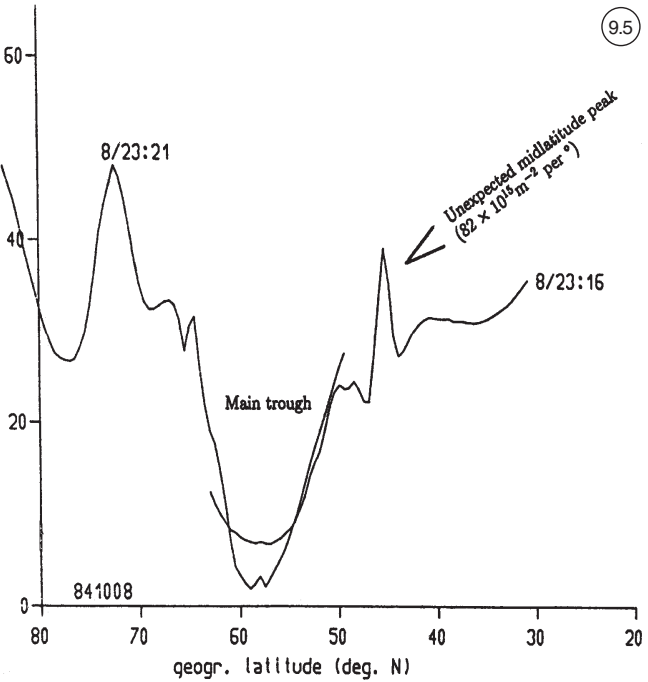

15 Nov $1987,9: 58$ UT

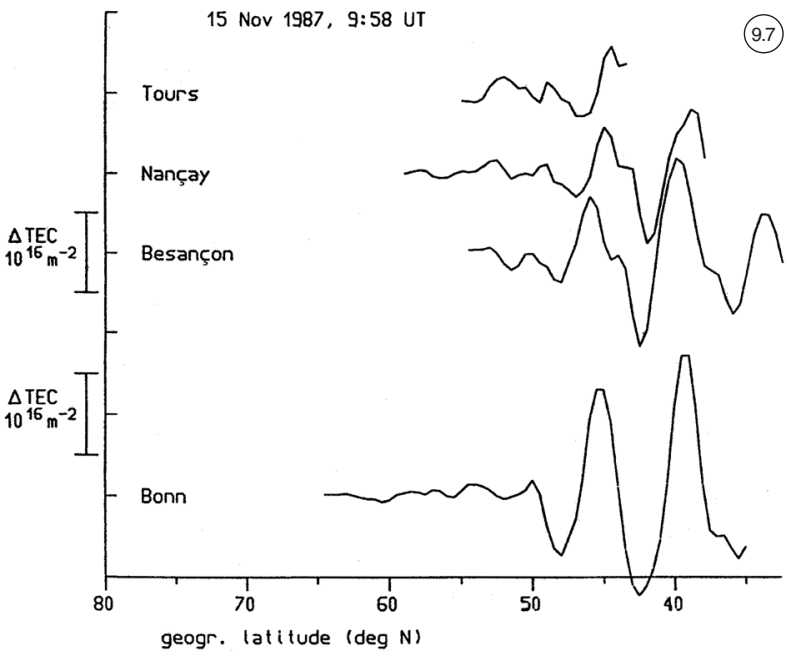

Fig. 9.5. Unexpected mid-latitude peak (sharp mid-latitude gradients) on 8 October 1984, around 23 LT (Leitinger, 1993). Electron content in units of $10^{16} \mathrm{~m}^{-2}$ versus geographic latitude from NNSS Diff. Doppler, receiving stations Graz (47.1N, 15.4E, right hand curve) and Uppsala (51.6N, 10.1E left hand curve). The midlatitude peak is clearly no artefact: it exists in 6 consecutive satellite passes recorded at Graz between about 20 h LT on October 8 and $01 \mathrm{~h}$ LT on October 9.

Fig. 9.6. Large amplitude TIDs from the Faraday effect on the VHF signals of the geostationary satellite SIRIO. High pass filtered TEC in units of $10^{15} \mathrm{~m}^{-2}$ versus time in hours UT.

Fig. 9.7. Example for strong latitudinal and longitudinal gradients from TIDs (Putz et al., 1990). High pass filtered electron content in units of $10^{16} \mathrm{~m}^{-2}$ versus geogr. latitude from NNSS Diff. Doppler, receiving stations Tours (47.4N, 0.7E), Nançay (47.3N, 2.2E), Besançon (47.3N, 6.0E), Bonn (50.5N, 6.9E). 

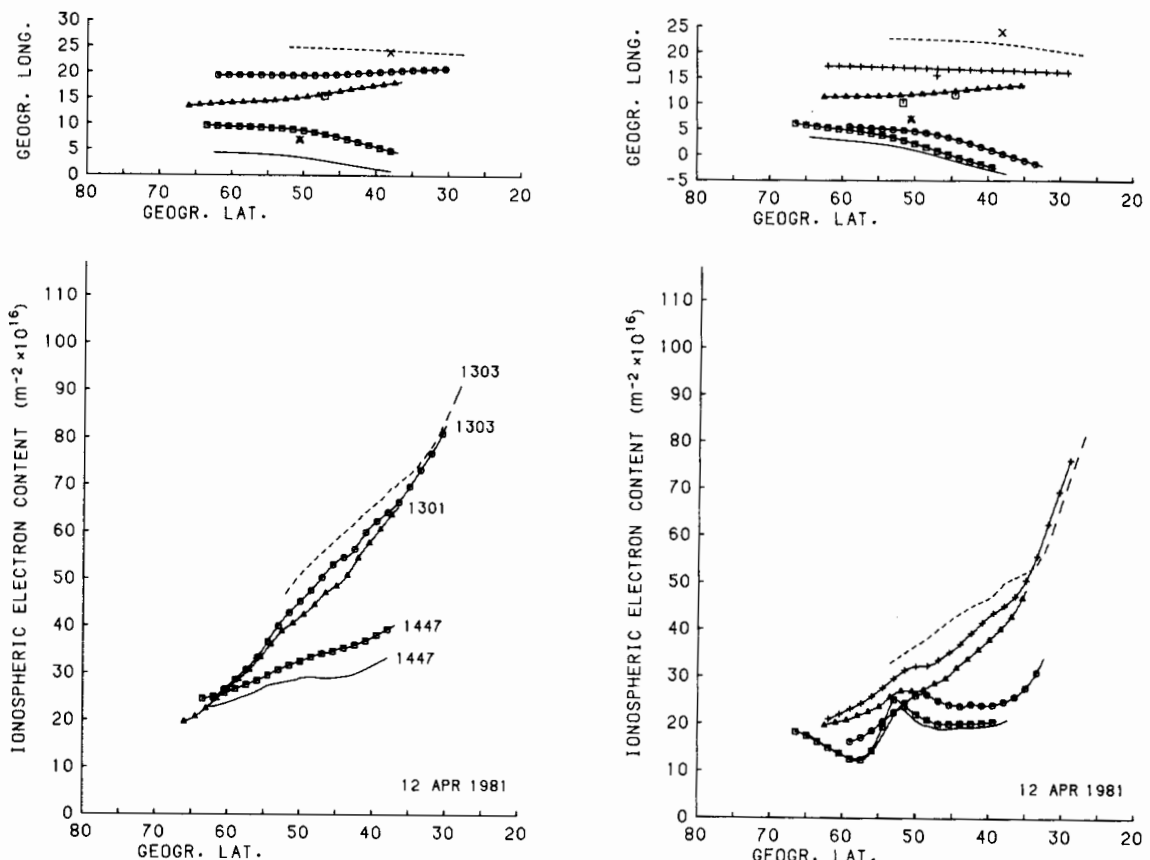

Fig. 9.8. Example for a regional negative storm effect (Leitinger et al., 1984). Latitude dependence of vertical electron content from the Differential Doppler effect on the 150/400 MHz signals of Navy Navigation satellites (NNSS). April 12, 1981, early afternoon (left) and late afternoon (right). Upper panels: maps of ionospheric points in a height of $400 \mathrm{~km}$ and receiving station locations (crosses). Receiving stations: Effelsberg $\left(50.5^{\circ} \mathrm{N}, 6.9^{\circ} \mathrm{E}\right)$, Lindau $\left(51.6^{\circ} \mathrm{N}, 10.1^{\circ} \mathrm{E}\right)$, Bologna $\left(44.6^{\circ} \mathrm{N}, 11.7^{\circ} \mathrm{E}\right)$, Graz $\left(47.1^{\circ} \mathrm{N}, 15.5^{\circ} \mathrm{E}\right)$, Dionysos $\left(38.1^{\circ} \mathrm{N}, 23.9^{\circ} \mathrm{E}\right)$. Local time for reaching the ionospheric points in $42.5^{\circ} \mathrm{N}$ and station symbols: (left hand side) $\mathbf{E}-$ solid, 14:53; $\mathbf{G}-$ squares, 15:11; $\mathbf{E}$ - triangles, 14:07; $\mathbf{G}$ - circles, 14:17; D - dashed, 14:33. (Right hand side) $\mathbf{E}$ - solid, 17:36; L - squares, 17:39; B - circles, 17:51; E - triangles, 16:48; G - plus signs, 17:02; D - dashed, 17:20.

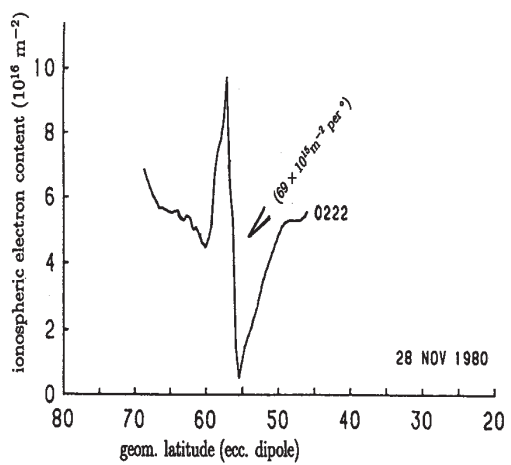

Fig. 9.9. Example for a very sharp trough region enhancement (Leitinger, 1993). Electron content in units of $10^{16} \mathrm{~m}^{-2}$ versus eccentric dipole latitude from NNSS Diff. Doppler, receiving station Uppsala (59.8N, 17.6E). Simultaneous observations from Lindau/Harz $(51.6 \mathrm{~N}, 10.1 \mathrm{E})$ prove that the Uppsala observations are not an artefact. Date: 28 November 1980; time: around 1:20 UT. 
Figure 9.8 gives an example for a negative storm effect confined to a rather narrow longitude zone. The electron content depression occurred west of $10^{\circ} \mathrm{E}$ and east of the American East Coast only. Central and Eastern Europe was not affected at all.

Figure 9.9 shows a very sharp electron content enhancement over the minimum of the main $F$-region trough. The latitudinal gradient of nearly 7 TEC units per degree can be considered as an «extreme of horizontal ionization gradient».

\subsection{CONCLusions}

The studies undertaken in the frame of COST 271 demonstrate that in mid latitudes and for statistics we can successfully transfer experience from ionogram derived $F 2$-layer peak density ( $N m F 2$ ) to vertical ionospheric electron content (vTEC). As for $f o F 2$ or $N m F 2$ we can derive monthly and hourly vTEC quantiles from Faraday rotation data on the signals of geostationary satellites if restricted to the range between the deciles.

Ionospheric vTEC data from GPS need an other approach: correction for the plasmaspheric contribution and the use of «voxels» (elements in geographic coordinates, local time and possibly also solar activity space with given intervals for each of these «coordinates»). The «voxel» approach was successfully used with latitudinal scans of vTEC from the Differential Doppler effect on the 150/400 $\mathrm{MHz}$ signals of the polar orbiting NNSS satellites (Feichter and Leitinger 1997)

Quantile statistics do not include the ionospheric signatures from «geophysical events», like magnetic storm effects, large scale and large amplitude TIDs, ridges, troughs and other structures which cannot be explained by means of external parameters like those for solar and geomagnetic activity. Since such «ionization extremes» might be of considerable interest for the planning and operation of application systems that make use of transionospheric propagation of radio signals, efforts should be made to complement existing case collections.

\section{ACKNOWLEDGEMENTS}

The work reported here was part of the COST 271/WG 2 activities. Thus the authors are grateful to the COST 271 members for participation and numerous helpful suggestions and discussion contributions. They also thank colleagues and collaborators in their institutions.

\section{REFERENCES}

CiraOlo L., and P. Spalla (1997): Comparison of ionospheric total electron content from the Navy Navigation Satellite System and the GPS, Radio Sci. 32, 1071-1079.

Ciraolo, L. and P. SPAlla (1998): Some results on GPS-NNSS TEC comparison, Acta Geod. Geophys. Hung., 33, 75-81.

CiRAOLO, L. and P. SPALla (1999): A statistics of time and space variability of ionospheric electron content at middle latitudes, in XXVI General Assembly URSI, 13-21 August 1999, Toronto, Canada.

Ciraolo L., P. Spalla and E. CAPAnnini (1994): Development of NNSS Differential Doppler Observations at Istituto di Ricerca sulle Onde Elettromagnetiche (IROE), in Proceedings of the International Beacon Satellite Sympium, Aberystwyth, U.K., edited by L. KERSLEY, 216-219.

Ciraolo L., M. Materassi and P. Spalla (2001): Comparison of TEC from NNSS and GPS from 1994 to 2000, on CD-BSS 2001, 4-6 June 2001, Boston College.

Davies, K. and X.M. LiU (1991): Ionospheric slab thickness in middle and low latitudes, Radio Sci., 26, 997-1005. 
FEICHTER, E. and R. LeITINGER (1997): The regional TEC model developed in Graz - A progress report, Acta Geod. Geophys. Hung., 32, 343-354.

Fox, M.W., M. Mendillo and J.A. Klobuchar (1991): Ionospheric equivalent slab thickness and its modeling applications, Radio Sci., 26, 429-438.

HAJEB-HosseinieH, H. and L. Kersley (1975): Analysis of satellite recordings, in Studies of Ionospheric Slab Thickness, Interim Scientific Report (Air Force Cambridge Res. Lab., Bedford, Mass., TR-75-0521), pp. 55.

HuAnG, Yinn-NiEN (1983): Some results of ionospheric slab thickness observations at Lunping, $J$. Geophys. Res., 88, 5517-5522.

JAKOwsKi, N., R. LeITINGER and L. CiRAOLO (2004): Behaviour of large scale structures of the electron content as a key parameter for range errors in GNSS applications, Ann. Geophysics, 47 (suppl. to no. 2/3), 1031-1047 (this volume).

KeRsley, L. and H. HAJEB-Hosseinieh (1976): The dependence of ionospheric slab thickness on geomagnetic activity, J. Atmos. Terr. Phys., 38, 1357-1360.

KLOBuchar, J.A., D.N. Anderson and P.H. DoherTy (1991): Model studies of the latitudinal extent of the equatorial anomaly during equinoctial conditions, Radio Sci., 26, 1025-1047.

KouRIS, S.S. and D.N. FotIADIS (2002): Ionospheric variability: a comparative statistical study, $A d v$. Space Res., 29, 977-985.

Kouris, S.S. and K.V. Polimeris (2003): TEC variability and extreme values, in Proceedings of the 3rd COST 271 Workshop, 23-27 September 2003, Spetses, Greece.

Kouris, S.S., Th. D. Xenos, K. V. Polimeris and D. STERgiou (2004): TEC and foF2 variations: preliminary results, Ann. Geophysics, 47 (4), (in press).

LEITINGER, R. (1993): The effects of horizontal gradients of ionization on position determination and the availability of relevant data, in Environmental Effects on Spacecraft Positioning and Trajectories, edited by A.VAllance Jones, Geophysical Monograph 73, IUGG 13, X, 39-45.

LeITINGER, R. (1998): Ionospheric electron content - The European perspective, Ann. Geofis., 41 $(5 / 6), 743-755$.

LeItingER, R. and E. FEICHTER (2000): COST-TEC - The electron content monthly median map adopted by COST 251, Phys. Chem. Earth (C), 25, 311-314.

Leitinger, R., G.K. HARTMAnN, F.-J. LOHMAR (1984): Electron content measurements with geo-detic Doppler receivers, Radio Sci., 27, 535-539.

Putz, E, R. Leitinger, G.K. Hartmann and P. Bencze (1990): TIDs observed by means of differential Doppler at four European stations during the TID campaign of November 1987, in Proceedings of the International Beacon Satellite Symposium (University of Tucumán, Argentina), 87-90.

Rawer, K. (1993): Wave Propagation in the Ionosphere (Kluwer Publ. Co., Dordrecht NL).

RAwER, K., S.S. KouRIS and D.N. FotiAdis (2003): Variability of $F 2$ parameters depending on modip, Adv. Space Res., 31, 537-541.

Spalla, P. and L. CiraOlo (1994): TEC and foF2 comparison, Ann. Geofis., XXXVII (5), 929-938.

Spalla P., E. Capannini, L. Ciraolo and R. Ragionieri (1983): Use of the VHF Signal of the SIRIO for Ionospheric Investigations, in Proceedings of the International Symposium on Beacon Satellite Studies of the Earth's Environment, New Delhi, edited by T.R. TYAGI, 415-428.

TithERIDGE, J.E. (1972): Determination of ionospheric electron content from the Faraday rotation of geostationary satellite signals, Planet. Space Sci., 20, 353-369.

Titheridge, J.E. (1973): The slab thickness of the mid-latitude ionosphere, Planet. Space Sci., 21, 1775-1793. 